\title{
Fusarium Crown Rot Whitehead Symptom as Influenced by Wheat Crop Management and Sampling Date
}

\author{
Richard W. Smiley \\ Emeritus Professor, Oregon State University, Columbia Basin Agricultural Research Center, Pendleton, OR 97801
}

\begin{abstract}
Symptoms of Fusarium crown rot of wheat include premature death of inflorescens (whiteheads), lesions on subcrown internodes, and rotting of crown tissue and lower stem internodes. Each symptom type is influenced by a different set of environmental conditions. Whiteheads are the easiest symptom to quantify and are frequently reported in the Pacific Northwest U.S.A. The objective of this research was to examine factors associated with whitehead expression and relationships with wheat yield and test weight. Incidence of whiteheads differed for inoculations with different isolates of $F$. pseudograminearum and $F$. culmorum, and over

and greatest expression of whiteheads differed among cultivars, which was associated in part with the cultivar heading date. Whiteheads were not correlated with subcrown internode lesions or browning of crown tissue. Whiteheads were also not correlated with grain test weight. Whiteheads were sometimes negatively associated with grain yield, but that relationship was variable and could not be considered a reliable, recurrent, or accurate measure of crown rot severity. These results indicate the need for caution in reporting whiteheads as a sole indicator of cultivar susceptibility to Fusarium crown rot.
\end{abstract} years due to weather factors. Whiteheads became less as planting dates for winter wheat were delayed until after September, and incidence was increased with increasing nitrogen application rate. Dates of initial
Keywords: Fusarium crown rot, wheat, Fusarium culmorum, Fusarium pseudograminearum, whitehead expression, wheat crop management
Fusarium crown rot (FCR; crown rot) of wheat (Triticum aestivum L.) in the Pacific Northwest (PNW) states of Idaho, Oregon, and Washington is caused by Fusarium pseudograminearum (O'Donnell \& Aoki) (=Gibberella coronicola ; formerly $F$. graminearum Group 1) and F. culmorum (Wm. G. Sm.) Sacc. (Cook 1968, 1980, 1981; Poole et al. 2013; Smiley and Patterson 1996). Grain yield reductions up to $35 \%$ have been measured in severely affected fields (Smiley et al. 2005b). The pathogens survive between crops mostly as mycelium and chlamydospores in dead wheat stems and crowns that became infected during growth of the previous crop (Burgess et al. 2001; Cook 1981). These infested residues remain intact at or near the soil surface during the 2-year winter wheat-fallow production cycle commonly practiced in rainfed fields of the semiarid PNW (Schillinger et al. 2006).

These fungi aggressively colonize seedling wheat tissues at or below the soil surface (Burgess et al. 2001; Cook 1981; Knight and Sutherland 2013). Soon after infection, the pathogens typically enter upon a period in which there is little or no increase in fungal biomass or symptom development (Beccari et al. 2011; Powell et al. 2016; Stephens et al. 2008). The disease process is strongly reactivated whenever infected plants are subjected to water stress (Beddis and Burgess 1992; Swan et al. 2000). The pathogens colonize the xylem and phloem in the crown and one to four lower internodes of the culm (Knight and Sutherland 2016). Affected stem and crown tissues are characterized by a brown discoloration that is often not observed by wheat producers. The most prominent symptom of severe crown rot is a premature senescence of heads (whiteheads) at the time when grain kernels are transitioning from the milk to the dough stage

Corresponding author: R. Smiley; richard.smiley@oregonstate.edu

Funding: This research was funded by the Oregon Wheat Commission, the USDA-Agricultural Research Service Cereal Root Disease Research Unit at Pullman, Washington, and the Oregon Agricultural Experiment Station.

The author(s) declare no conflict of interest.

Accepted for publication 24 April 2019.

(C) 2019 The American Phytopathological Society
(Zadoks growth stages 75 to 85; Zadoks et al. 1974). Whiteheads become particularly prevalent when plants are stressed by drought near the end of the growing season (Hollaway and Exell 2010; Liu and Liu 2016; Smiley et al. 2009). However, they are usually visible for only a few days or up to one week, depending upon influences of weather, soil moisture, and disease severity.

Development of stem browning and whiteheads are each strongly influenced by environmental conditions. These different quantifiable measures of crown rot incidence and severity are sometimes poorly correlated (Smiley 2019; Smiley et al. 2005b), but each has been found to be negatively correlated with grain yield in some instances (Burgess et al. 2001; Dodman and Wildermuth 1987; Dodman et al. 1985; Purss 1966; Wildermuth and McNamara 1994). Basal stem browning is considered the most reliable symptom (Burgess et al. 2001). While most reports of culm browning are from samples collected at the time of harvest, Knight and Sutherland (2015) found that this symptom was correlated most highly with the mass of fungal mycelium inside tissues when sampling was done at the time of plant anthesis rather than at harvest. Measurement of culm browning is very labor intensive and most easily and commonly accomplished on stubble remaining after grain harvest.

Counts of whiteheads is the easiest and most rapid estimate of crown rot incidence, but this symptom is especially affected by environmental conditions (Burgess et al. 2001; Cook 2017; Dodman and Wildermuth 1987; Klassen et al. 1992; Klein et al. 1991; Smiley 2009; Smiley et al. 2005a). Whiteheads rarely form if an adequate supply of water is available near the end of the growing season (Burgess et al. 2001; Klein et al. 1991; Smiley et al. 2009). Interactions of the wheat production system and availability of soil water are also important in regions where plants reach maturation when the only water available is stored deeply in the soil profile. In low precipitation areas of the PNW, where rainfall is sparse to nonexistent during midsummer, fewer whiteheads are expressed as the distance between winter wheat rows is increased, distance between wheat plants within a row is increased, preplant nitrogen fertilizer is applied at lower rates, and where wheat is planted later during the autumn (Cook 1981, 2017; Papendick and Cook 1974). Each of these agronomic practices increases the amount of water available to individual plants.

Counts of whiteheads sometimes strongly underestimated crown rot incidence and the effect of crown rot on yield in the northern wheat belt of eastern Australia, where precipitation often occurs 
during the summer at the time wheat is maturing (Klein et al. 1991). The incidence of symptomless (no whitehead expression) infected plants with brown culms was relatively low during most years but rose to 57\% during a growing season (1981) with extreme variation in rainfall during successive multimonth periods (Klein et al. 1991). In the PNW, significant rainfall ( $>5 \mathrm{~mm} /$ month) seldom occurs during the summer and there is typically sufficient water stored in the deep silt loam profiles to enable the crop to mature without moisture stress. Under those conditions, Smiley et al. (2005b) reported that aboveground symptoms of crown rot, particularly whiteheads, were not always apparent under conditions of moderate infection and moderate yield constraint. Nevertheless, investigators in the PNW continue to quantify whiteheads as a rapid and inexpensive estimate of crown rot incidence and severity.

While it is known that whitehead expression is affected by lateseason water stress induced by factors such as early planting and high rates of nitrogen application, there are few or no reports of whether individual cultivars differ in response to the other agronomic variables. The objectives of this paper were to define the variability of whitehead expression among different isolates and species of Fusarium, and among cultivars. Data were taken from six crown rot experiments conducted in the semiarid wheat-producing region of eastern Oregon. Influences evaluated were the aggressiveness of different isolates, the timing and rate of nitrogen application, the wheat planting and heading dates, and the timing of whitehead counts.

\section{Materials and Methods}

Experimental sites. Experiments were performed on naturally infested wheat fields near the Oregon communities of Moro (Sherman County; $45.4852^{\circ} \mathrm{N}, 120.7167^{\circ} \mathrm{W}$ ) and Pendleton (Umatilla County; $\left.45.7120^{\circ} \mathrm{N}, 118.6278^{\circ} \mathrm{W}\right)$. Twenty-year mean annual precipitations at these locations are 275 and $427 \mathrm{~mm}$, respectively (Table 1), with more than $75 \%$ of precipitation occurring from October through May. Soils at both locations are deep Walla Walla silt loams; Typic Haploxerolls. Most agricultural land (95\%) in each area is planted to soft white winter wheat exported for use in producing low-protein products overseas. Spring wheat is planted in March (spring) and harvested in July or August (summer), and is often produced in rotation with winter wheat, fallow, and possibly a food legume or oilseed crop. Winter wheat is planted during September or October (autumn) and is harvested about 10 months later during July or August. The winter wheat-fallow system is fallowed for a 14-month period to accumulate soil moisture before the next wheat crop is planted (Schillinger et al. 2006). Winter wheat stubble remains upright during the winter after harvest, and soil is cultivated with a chisel plow followed by a rod weeder during the spring. Additional passes of the rod weeder may occur during the summer to control weeds during the 14-month fallow period and to maintain a surface 'dust' mulch that inhibits evaporative moisture loss from the surface. All nitrogen fertilizer required for the next wheat crop is typically shanked into soil prior to a pass of the rod weeder during late spring of the fallow year.

In this study, the rate of fertilizer application was determined from results of soil testing and differed among experiments. Herbicides were also applied in accordance with industry standards to kill weed species present at each site.

A mixture of native populations of $F$. pseudograminearum and $F$. culmorum are endemic and spatially heterogeneous (Poole et al. 2013; Smiley and Patterson 1996; Smiley et al. 2013, 2016). Pathogens were periodically isolated and identified from infested pieces of browned stubble after the previous harvest, but no attempt was made to quantify the pathogens.

Six experiments were established to examine effects of crop management and cultivars on expression of whiteheads. Studies included inoculations with different isolates of crown rot pathogens, and the timing and rate of nitrogen application, wheat planting, and heading dates, and timing of whitehead counts.

Pathogen isolates and whitehead counting dates for spring wheat. PNW isolates of $F$. pseudograminearum and $F$. culmorum exhibited a wide range of aggressiveness in greenhouse and field tests with spring wheat (Smiley et al. 2005a). Whitehead data for that experiment were not reported. This paper compares whiteheads induced on spring wheat inoculated with six representative isolates of each species. The isolates were collected from symptomatic plant crowns and subcrown internodes in Oregon and Washington (Smiley and Patterson 1996). Isolates were identified morphologically using wheat-leaf agar for spore and conidiophore morphology and potato-dextrose agar for color characteristics (Nelson et al. 1983). Twenty-one isolates were then screened for aggressiveness in the greenhouse and on spring wheat in the field (Smiley et al. 2005a). Six isolates of each species, with different levels of aggressiveness and geographic origins, were selected for reporting in this paper: $F$. pseudograminearum isolates 93 033-02, 93 033-13, 93 041-06, 93 033-33, 94 006-11, and 94 032-06, and F. culmorum isolates 93 040-04, 93 044-05, 93 089-07, 93 094-11, $93103-10$, and $93113-05$. Identity of the 12 isolates was confirmed using polymerase chain reaction tests described by Schilling et al. (1996) and Williams et al. (2002).

Identical experiments were conducted at two locations (Pendleton and Moro) over a period of 2 years; 2003 and 2004. Untreated seed of spring wheat cv. 'Zak' was planted uniformly at a rate of 270 seeds/ $\mathrm{m}^{2}$ into a field during early March at each location during each year. A 4-row John Deere deep-furrow seed drill placed the wheat seed at 2-cm depth at Pendleton and 3-cm depth at Moro. The four rows were spaced $25 \mathrm{~cm}$ apart and were $12 \mathrm{~m}$ long.

Table 1. Twenty-year mean annual precipitation $(\mathrm{mm})$ at Pendleton and Moro, OR and amounts during years in which experiments were performed; precipitation totals for the winter wheat crop year (September 1 - August 31), spring months (March - June), and kernel maturation period (May - June)

\begin{tabular}{|c|c|c|c|c|c|c|c|c|}
\hline \multirow[b]{2}{*}{ Experiment name } & \multirow[b]{2}{*}{ Crop $^{z}$} & \multirow[b]{2}{*}{ Harvest year } & \multicolumn{2}{|c|}{ Crop year } & \multicolumn{2}{|c|}{ Spring } & \multicolumn{2}{|c|}{ Maturation } \\
\hline & & & Pendleton & Moro & Pendleton & Moro & Pendleton & Moro \\
\hline \multicolumn{3}{|c|}{ 20-year mean annual precipitation } & 427 & 275 & 165 & 86 & 75 & 40 \\
\hline \multirow{2}{*}{ Pathogen isolates } & $\mathrm{SWc}$ & 2003 & 398 & 236 & 192 & 54 & 26 & 5 \\
\hline & & 2004 & 509 & 303 & 168 & 87 & 51 & 51 \\
\hline \multirow[t]{2}{*}{ Fertilizer } & WWc & 1993 & 541 & 342 & 100 & 132 & 91 & 58 \\
\hline & & 1994 & 317 & 149 & 135 & 55 & 92 & 31 \\
\hline Planting date & WWc & 1997 & 550 & - & 178 & - & 40 & - \\
\hline \multirow[t]{2}{*}{ Sampling date } & WWc & 2001 & 420 & - & 147 & - & 56 & - \\
\hline & & 2002 & 331 & - & 125 & - & 61 & - \\
\hline \multirow[t]{2}{*}{ Sampling date } & $\mathrm{WWb}$ & 2002 & 331 & - & 125 & - & 61 & - \\
\hline & & 2003 & - & 236 & - & 54 & - & 5 \\
\hline \multirow[t]{4}{*}{ Heading date } & $\mathrm{WWc}+\mathrm{b}$ & 2014 & - & 259 & - & 97 & - & 26 \\
\hline & & 2015 & - & 255 & - & 21 & - & 9 \\
\hline & & 2016 & - & 268 & - & 63 & - & 25 \\
\hline & & 2017 & - & 294 & - & 121 & - & 28 \\
\hline
\end{tabular}

${ }^{\mathrm{z}} \mathrm{SWc}=$ commercial spring wheat cultivars, WWc $=$ commercial winter wheat cultivars, WWb $=$ winter wheat breeding lines, WWc $+\mathrm{b}=$ mixtures of commercial and breeding entries. 
Millet seed inoculum was prepared as described by Smiley (2019). Briefly, the pathogens were isolated from infested winter wheat crowns and identified using morphological features (Nelson et al. 1983). Isolates were stored at $4^{\circ} \mathrm{C}$ on autoclaved barley seed. Inoculum was prepared from colonies growing on 0.2-strength potatodextrose agar medium. Squares of colonized agar medium were transferred into flasks containing twice-autoclaved millet seeds. Flasks were shaken intermittently for 2 weeks to reduce clumping, and the thoroughly colonized millet was air-dried at room temperature (ca. $24^{\circ} \mathrm{C}$ ) in paper bags. Dried millet seeds were sieved to produce a whole-seed inoculum substrate with approximately 200 seeds per gram. Two rows on one side of each 4-row seeded plot were inoculated by manually placing $2.3 \mathrm{~g}$ millet seed inoculum $/ \mathrm{m}$ of row about $2 \mathrm{~cm}$ above the wheat seed in 12-m-long plots. The 2-row plots inoculated with individual isolates were not replicated.

Seedling density in each plot was counted in two 1-m row lengths of inoculated and noninoculated rows of each treatment during late March. Each of those row sections was marked with a flag. Whiteheads and total heads were counted in the same row sections during June. Whitehead counts were repeated on as many dates as possible for each location and year. Total whiteheads in two rows of each plot were averaged across rows and converted to whiteheads $/ \mathrm{m}$ of row. Percentage whitehead data were normalized using the arcsine transformation (arcsine $\sqrt{ }[\% / 100])$, and seedling density was normalized by applying the square-root transformation. Transformed data were analyzed as described in the results section, using CoStat Statistical Software version 6.4 (CoHort Software, Monterey, CA). Means were separated using Fisher's least significant difference test $\left(\mathrm{LSD}_{0.05}\right)$. Variables included two years, two locations, two inoculations (plus or minus), two Fusarium species, and six isolates. Samples of plants expressing whiteheads were collected from selected plots, and isolations were made to confirm that whiteheads were caused by the Fusarium species placed into each plot, either $F$. pseudograminearum or $F$. culmorum. Grain was not harvested.

Fertilizer management for winter wheat. The effect of fertilizer timings and rates on crown rot of four winter wheat cultivars was examined at naturally infested locations near Moro and Pendleton over two growing seasons: 1992-1993 and 1993-1994. Nine fertilizer treatments consisted of 1) no nitrogen applied, 2) $45 \mathrm{~kg} \mathrm{~N} / \mathrm{ha}$ as anhydrous ammonia shanked into fallow before planting winter wheat, 3 ) $45 \mathrm{~kg} \mathrm{~N} / \mathrm{ha}$ as aqueous ammonia applied with a point-injection system immediately before planting, 4) $45 \mathrm{~kg} / \mathrm{ha}$ applied by point injection into the crop during April, 5) $45 \mathrm{~kg} / \mathrm{ha}$ applied as $22.5 \mathrm{~kg} / \mathrm{ha}$ into fallow and $22.5 \mathrm{~kg} / \mathrm{ha}$ during April, 6) $45 \mathrm{~kg} / \mathrm{ha}$ applied as $22.5 \mathrm{~kg} / \mathrm{ha}$ at planting and $22.5 \mathrm{~kg} /$ ha during April, 7) $22.5 \mathrm{~kg} \mathrm{~N} / \mathrm{ha}$ applied in fallow, 8) $22.5 \mathrm{~kg} / \mathrm{ha}$ applied at planting, and 9) $22.5 \mathrm{~kg} / \mathrm{ha}$ applied as $11.3 \mathrm{~kg} / \mathrm{ha}$ at planting and $11.3 \mathrm{~kg} / \mathrm{ha}$ applied in April.

Anhydrous ammonia was shanked into fallow at $15-\mathrm{cm}$ depth and at $30-\mathrm{cm}$ shank spacings during the summer before wheat was planted. Shortly before planting in early October, aqua ammonia was injected at $10-\mathrm{cm}$ depth in a grid pattern with injection points located $30 \mathrm{~cm}$ apart (Baker et al. 1989). The same injector was used to make in-crop applications during the spring.

Four replicates of four cultivars ('Hyak', 'Madsen', 'Malcolm', and 'Stephens') were planted into $4 \times 7 \mathrm{~m}$ plots within each of the nine fertilizer treatments. Wheat was planted at a rate of 194 seeds $/ \mathrm{m}^{2}$ and in early October by using a Hege double-disk drill with $25-\mathrm{cm}$ row spacings and 3-cm depth at Pendleton, and a John Deere HZ deep-furrow drill with $35-\mathrm{cm}$ row spacings and 7-cm depth at Moro. Different fields were used each year at each location due to the 2-year cycle of the wheat-fallow system.

Total whiteheads in two entire rows of each plot were counted in June of each year. Data were averaged across rows and converted to whiteheads/m of row. Grain was harvested from each plot using a Hege 140 small-plot combine after grain had dried to less than $12 \%$ moisture. Grain yield and test weight were determined using standard procedures. Data are reported for only the second year at both locations because higher-than-average precipitation caused few whiteheads to occur during the first year. Data were analyzed as a strip-split plot with fertilizer as the strip factor, cultivar as the main plot factor, and location as the subplot factor.

Planting date for winter wheat. The influence of planting dates on water-use efficiency and grain yield of four winter wheat cultivars was studied at Pendleton during three crop years, as described by Chen et al. (2003). Results of crown rot data collected during the first year (1997) were not published. Briefly, the experiment consisted of four replicates of four cultivars ('Gene', 'Madsen', 'Rohde', and 'Stephens') planted into $3 \times 9 \mathrm{~m}$ plots at completely randomized locations within six planting date blocks each year. Whitehead data were collected from four planting dates: 3 and 20 September, 10 October, and 1 November, and are the only plantings reported in this paper.

Planting equipment and depth differed to match industry standards for these planting dates, considering factors such as soil temperature, depth of surface dust mulch, soil moisture, anticipated precipitation, and predicted productivity. During September, wheat was planted using a John Deere HZ split-packer deep-furrow drill with 36-cm row spacing and a seeding rate of 194 seeds per $\mathrm{m}^{2}$. Seeds were planted 8- to10-cm depth below the soil surface resulting in seed placement $2 \mathrm{~cm}$ into moist soil with an overburden of air-dry soil up to $4 \mathrm{~cm}$ deep at the bottom of surface furrows. The last two plantings were made using a seeding rate of 280 seeds per $\mathrm{m}^{2}$ and a Hege 55 plot drill equipped with different openers to place seeds at different depths depending on soil moisture and temperature. In October, seed was planted at 6-cm depth by using 'Gaines' hoe-type openers at 30-cm row spacing. In November, seed was planted at 1-cm depth using double-disc openers at $15-\mathrm{cm}$ row spacing.

Wheat seed was commercially treated with carboxin, thiram, and lindane (Vitavax-Thiram-Lindane; Gustafson LLC, Plano, TX) at application rates used for commercial crops. Each cultivar was planted into $3 \times 9 \mathrm{~m}$ plots replicated four times in a completely randomized design within each planting-date block. These blocks were nonreplicated and positioned sequentially in the field.

Plants with intact root systems were dug from three randomly selected positions in each plot during late March. Roots were rinsed to remove adhering soil, and 15 plants from each plot were evaluated visually for incidence and/or severity of crown rot. Incidence was quantified as percentage of subcrown internodes affected by characteristic dark lesions. Severity was assigned as a rating scale: $0=$ no lesion on the subcrown internode, $1=1$ to $25 \%$ of area affected by lesion(s), $2=26$ to $50 \%$ lesion area, $3=51$ to $75 \%$ lesion area, and $4=>75 \%$ lesion area.

Whiteheads and total heads in two entire rows were counted during mid-June 1997. Data were averaged and converted to whiteheads/m of row. Data for percentages of plants with subcrown internode lesions and whiteheads were normalized using the arcsine transformation (arcsine $\sqrt{ }[\% / 100])$. Transformed data were analyzed as a split plot with planting date as the main plot and cultivar as the subplot. Means for factors were separated using Fisher's least significant difference test $\left(\mathrm{LSD}_{0.05}\right)$. Nontransformed means are reported.

Grain was harvested during mid-July to measure grain yield and test weight. Results were reported (Chen et al. 2003) and are not repeated here.

Whitehead sampling date for commercial winter wheat cultivars. During the course of the two previously described experiments, it became apparent that whiteheads appeared at slightly different times for different cultivars. An experiment was therefore conducted over 2 years (2000-2001 and 2001-2002) at Pendleton to determine whether the number or percentage of whiteheads varied among cultivars during repetitive observations at 2- to 3-day intervals. Nineteen commercial cultivars of winter wheat and one of winter triticale were planted into side-by-side 9-m-long plots that were either treated or not treated with a mixture of five isolates of $F$. pseudograminearum, as described by Smiley (2019). The experimental design was a split-split plot with cultivar as main plot and inoculum as subplots in blocks replicated four times.

Wheat seed was treated with difenoconazole plus mefenoxam (Dividend XL + Ridomil; $24.2+0.09 \mathrm{~g}$ a.i. $/ \mathrm{kg}$ of seed) and planted using a 4-row John Deere HZ split-packer deep-furrow drill with hoe-type row openers at $36-\mathrm{cm}$ spacing, as described by Smiley 
(2019). Wheat seed was dispensed through a cone planter and placed $2 \mathrm{~cm}$ into moist soil below a variable depth overburden of air-dry soil (dust mulch). The mixed-isolate whole millet seed inoculum was metered at a rate of $2.3 \mathrm{~g} / \mathrm{m}$ of row (about 460 millet seeds $/ \mathrm{m}$ ) from a 4-row Gandy Multi-Purpose Seed/Fertilizer/Granular Chemical Applicator (Gandy Company, Inc., Owatonna, MN) mounted on the seed drill and operated through a ground-driven Zero-Max Adjustable Speed Drive (Zero-Max Inc., Plymouth, MN). The inoculum was dispensed into tubes mounted behind each drill opener and separate from the tubes used to dispense the wheat seed from the seed cone. Inoculum was placed $2 \mathrm{~cm}$ above the wheat seed. Drill strips were flagged for continuous runs across all replicates and then alternate drill strips were planted without dispensing inoculum. The same sequence of each cultivar was then planted while dispensing inoculum into the remaining drill strips.

Plants with intact root systems were dug during April to assess incidence of lesions on subcrown internodes, as described previously. Additionally, crowns were split with a knife to assess the percentage of plants with brown (rotted) internal tissue.

Whiteheads in two entire rows of each plot were counted on alternate days over a 10-day period from 15 June to 3 July 2001. The whiteheads were counted each day by walking in the middle of the 4-row plot in the direction that best eliminated glare from the sun. All plots were counted by walking in the same direction and traversing across all replicates during a single pass. The author was unfamiliar with the phenotypic appearance of most cultivars. Nevertheless, to avoid the possibility of phenotypic recognition, data were recorded on plot diagrams labeled with only the planting order for each combination of cultivar, inoculum, and replicate; e.g., a continuous numbering from 1 to 160 . Total heads in each row were also counted on the first counting date, after all whitehead counts had been completed. Percentage whitehead data were averaged across rows for each sampling date, cultivar, inoculum, and replicate. Grain was harvested with a small plot combine to determine grain yield and test weight, using standard procedures.

The experiment was repeated the following year, using three replicates of the same 20 cultivars. Whiteheads were counted on 30 June and 3 July 2002.

Percentage whitehead data were normalized by arcsine transformation and analyzed individually by year and sampling date as a split-split plot design with cultivar as the main plot and inoculation as the subplot. Percentage lesion incidence and crown browning were also transformed and analyzed individually by year using cultivar as main plot and inoculation as subplot. Grain yield and grain test weight data were normalized using the square-root transformation and analyzed for individual years. Means for factors were separated using Fisher's least significant difference test $\left(\mathrm{LSD}_{0.05}\right)$.

Whitehead sampling date for winter wheat breeding lines. This experiment had a similar objective as the preceding experiment but differed in that it included two replicates of 50 elite winter wheat breeding lines planted at Pendleton during the 2001-2002 winter wheat crop year. The 4-row deep-furrow seed drill was configured to deposit inoculum from only two openers on one side of the drill. Percentage of plants with subcrown internode lesions was evaluated in late March. All whiteheads in both 9-m-long rows of each inoculum treatment were counted on 30 June and 3 July 2002. Total heads were also counted on the first sampling date. Grain was harvested from each 2-row plot using a small plot combine. Data were analyzed as described previously.

The experiment was repeated the following year (2002-2003) with an expanded list of 100 wheat entries replicated four times at Moro. The entries included 86 breeding lines and 14 commercial cultivars. Plots were $6 \mathrm{~m}$ long and consisted of inoculated and noninoculated 2row plots for each wheat entry. Severity and incidence of lesions on subcrown internodes, and percentages of browned crowns were evaluated in late March. Whitehead counts were made on 13, 17, and 19 June 2003, and total heads were counted on 20 June. Grain was harvested and data were analyzed as described previously.

Heading date for winter wheat cultivars. During the course of these studies, it became important to examine the hypothesis that expression of whiteheads in cultivar screening nurseries was influenced in part by differences in cultivar heading dates. However, multicultivar trials rarely include data for both heading date and whiteheads. It was possible to evaluate that relationship using replicated data from eight trials planted near Moro and published by the Oregon State University Cereals Testing Program (https://agsci. oregonstate.edu/wheat/osu-wheat-variety-trials). Treatment means for cultivar heading date, whiteheads, grain yield, test weight, and other agronomic traits were posted for the 4-year period; 2014 to 2017. Two nurseries of importance for this evaluation were planted each year; the Oregon Soft White Winter Wheat Elite Yield Trial (OWEYT) and the Oregon Hard Winter Wheat Elite Yield Trial (HWEYT). Grain yields were not reported for the 2017 HWEYT nursery. Whitehead counts were made on a single date during June of each year. In most cases, whitehead, heading, and grain yield data were posted for the same trial. Where heading data were lacking, it was taken from an identical trial planted at a nearby location. For one trial, heading date data from 2016 was used to compare with whitehead data reported during 2015, resulting in fewer cultivars for comparison because these trials contained a different list of entries each year.

Linear and quadratic regression analysis were used to evaluate associations between whiteheads and heading date, and between whiteheads and grain yield. For these analyses, data were normalized. Percentage whiteheads was transformed using the natural logarithm, and grain yield was transformed using the square-root transformation. Because rankings of heading dates differed slightly over years, comparisons were based upon the difference of heading dates for individual cultivars and that of the check cultivar Bobtail. Negative numbers were removed by adding 10 days to each datum point.

\section{Results}

Pathogen isolates and whitehead counting dates for spring wheat. Whiteheads on spring wheat at Moro could be counted on two dates during 2003 and four dates during 2004. Whiteheads at Pendleton could be counted only once each year. The maximum whitehead count for each fungal isolate at each location and year was used for analysis. Precipitation was greater at both locations during 2004 than 2003, particularly during the time of kernel maturation (Table 1).

Initial analysis of whitehead data using a 3-way completely randomized design without replication indicated that there were significant differences for effects of year $(P<0.0001)$ but not location or isolate. Data were therefore grouped over locations and isolates for a 3-way randomized complete block analysis using main effects of inoculation (plus or minus), Fusarium species, and year. The main effects for year and inoculation were significant at $P<0.0001$, and the main effect for species was significant at $P=0.0365$. Whitehead percentages were greater $\left(\mathrm{LSD}_{0.05}=0.5\right)$ during 2003 than 2004 (means of $3.3 \%$ versus $1.5 \%$ ), greater in the inoculated than in the control treatment (3.2\% versus $1.6 \%)$, and greater when inoculated with $F$. pseudograminearum than $F$. culmorum $(2.7 \%$ versus $2.1 \%)$. The year $\times$ inoculation interaction was significant at $P=0.0056$, indicating that the differences in whitehead percentages in inoculated versus control plots were greater during the first year 2003 (4.3\% versus $2.1 \%)$ than 2004 (1.7\% versus $1.1 \%)$

Although differences among nonreplicated isolates could not be analyzed, the individual isolates of both species clearly differed in their ability to cause whiteheads, as illustrated by data from Moro during 2004 (Fig. 1). In the inoculated treatment, six isolates of $F$. culmorum caused an apparent maximum percentage of whiteheads to vary from about $0.6-3.7 \%$. The apparent range was greater $(1.0-8.0 \%)$ for the six isolates of $F$. pseudograminearum. However, those values included the whiteheads caused by both the inoculum and the native population, as could be quantified by comparing adjacent pairs of inoculated and control rows. The percentages of whiteheads also varied among replicates of plots in the noninoculated treatment for each isolate, reflecting the spatial heterogeneity of the native pathogen population. To determine the effect of the inoculated isolate in two rows of each 4-row plot, the percentage of whiteheads 
in the control rows were subtracted from those in the inoculated rows. Results shown in Figure 1 indicated that the apparent aggressiveness of individual isolates could be quite different when the background level of whitehead development was subtracted from the total. Most notably, the range of additional whitehead expression due to inoculation became much reduced when compared with that observed in the controls. For example, isolate $F$. culmorum 93 044-05 caused an apparent maximum of $2.0 \%$ whiteheads, but when the background level was subtracted that isolate only increased whiteheads by $0.2 \%$. The most-aggressive isolate of $F$. culmorum, 93 113-05, caused a maximum of $4.0 \%$ whiteheads, which was reduced to $2.5 \%$ after the background level had been subtracted. Likewise, plots inoculated with isolate $F$. pseudograminearum 93 033-02 had an apparent maximum of $4.9 \%$ whiteheads, but the adjusted value was $1.2 \%$. An aggressive isolate of $F$. pseudograminearum, 94 032-06, had a maximum of $7.9 \%$ whiteheads, with an adjusted value of $6.1 \%$. Another apparently aggressive isolate, $F$. pseudograminearum 93093 04 , had a maximum of $8.0 \%$ whiteheads but an adjusted value of about $4.0 \%$ throughout the 15 -day counting period, suggesting that all of the apparent increase in percentage whiteheads in those plots was caused by the background populations of Fusarium in those rows of the nursery.

Fertilizer management for winter wheat. Greater than normal precipitation at Pendleton and Moro during 1993 (Table 1) caused very few whiteheads to occur; means were 1.0 and $1.3 / \mathrm{m}$ of row at Pendleton and Moro, respectively. The second crop year (1994) was much drier than normal at Pendleton and Moro and resulted in a much greater expression of whiteheads. Data for 1994 are reported.

The location, cultivar, and fertilizer factors were each significant at $P=0.0001$. There was also a significant location $\times$ cultivar interaction $(P=0.0178)$. Mean whitehead counts were 14.5 and $28.9 / \mathrm{m}$ of row at Pendleton and Moro, respectively; $\mathrm{LSD}_{0.05}=4.7$. Means for cultivars Madsen, Hyak, Stephens, and Malcolm were $13.2,16.2,23.1$, and $34.2 / \mathrm{m}$ of row, respectively; $\mathrm{LSD}_{0.05}=6.0$. Four of the five $45 \mathrm{~kg} \mathrm{~N} / \mathrm{ha}$ treatments had more whiteheads $(25.4-29.3 / \mathrm{m}$ of row) than the three $22 \mathrm{~kg} / \mathrm{ha}$ treatments (16.0-23.7/m of row) and the nonfertilized control $(10.6 / \mathrm{m}$ of row $) ; \mathrm{LSD}_{0.05}=6.9$.

The two most susceptible cultivars (Malcolm and Stephens) were reanalyzed separately by grouping the fertilizer treatments by total amount of nitrogen applied. The location and fertilizer factors were significant at $P=0.0025$ and $P=0.0045$, respectively. Mean whitehead counts were 17.9 and $39.5 / \mathrm{m}$ of row at Pendleton and Moro, respectively; $\mathrm{LSD}_{0.05}=10.6$. The nitrogen rates of 0,22 , and $45 \mathrm{~kg} \mathrm{~N} / \mathrm{ha}$ had $15.1,25.0$, and 33.6 whiteheads $/ \mathrm{m}$ of row; $\mathrm{LSD}_{0.05}=11.7$, with 16,48 , and 80 degrees of freedom for these groupings. Cultivar means shown in the previous paragraph did not differ significantly; $P=0.0629$. The fertilizer rate $\times$ location interaction was significant at $P=0.0314$.

When the cultivars Malcolm and Stephens were analyzed separately for the various application timing treatments within either the 22 or $45 \mathrm{~kg} \mathrm{~N} / \mathrm{ha}$ application rates, there was no significant application timing effect at either rate of total application. The location effect was significant for the $45 \mathrm{~kg} / \mathrm{ha}$ rate $(P=0.0438)$ but not for the $22 \mathrm{~kg} / \mathrm{ha}$ application rate, and there were no significant interactions.

Total nitrogen clearly had a greater effect on whitehead formation than the timing or method of application. Percentage whiteheads were not significantly correlated $(P<0.10)$ with grain yield or test weight (data not presented).

Planting date for winter wheat. Plant sampling during the spring of 1997 revealed that the native Fusarium population caused a high
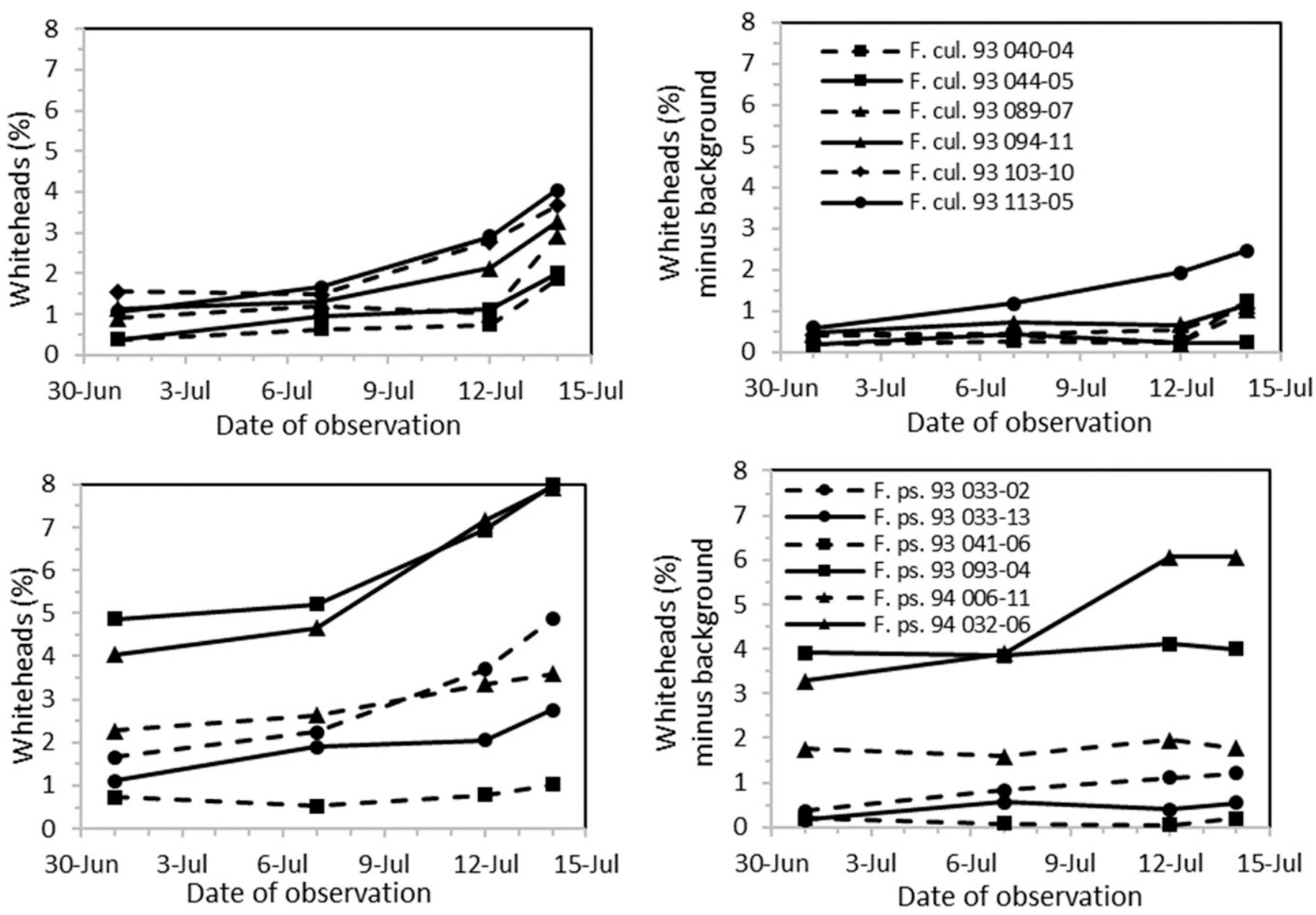

Fig. 1. Whiteheads exhibited during four dates of observation in spring wheat cv. Zak growing in plots inoculated with individual isolates of Fusarium culmorum (top row) or F. pseudograminearum (bottom row) at Moro, OR during 2004; whiteheads are expressed as a percentage of total heads (left column) and as the difference in percentage of whiteheads in inoculated and adjacent control plots (right column). Lines and markers are the same for each fungal isolate within the same row. 
percentage of subcrown internodes to exhibit lesions on all cultivars during the first three planting dates (Table 2) during a year of plentiful precipitation during the crop year and spring, but a relatively dry period during grain maturation (Table 1). Lesions were significantly $(P<0.0001)$ affected by planting dates, cultivars, and the interaction of these factors. Lesions became less numerous with the four successive planting dates; $39.6,40.4,25.5$, and $3.3 \%$, respectively; $\mathrm{LSD}_{0.05}=$ 3.4. Greater percentages of lesions occurred on Gene and Madsen than on Stephens and Rohde; 30.4, 29.8, 24.4, and 24.1\%, respectively; $\mathrm{LSD}_{0.05}=2.6$. The significant cultivar $\times$ planting date interaction indicated that the greatest percentages of lesions occurred at different planting dates for individual cultivars. For instance, the highest percentage occurred on Madsen and Gene during the first and second planting dates, respectively (Table 2). The percentage lesions decreased more during the third planting date for Gene than for the other three cultivars.

Whiteheads caused by crown rot were significantly $(P<0.0001)$ affected by planting date, cultivar, and the cultivar $\times$ planting date interaction. Whitehead expression differed over the four planting dates; 15.5, 24.9, 3.7, and 2.2\% $\left(\operatorname{LSD}_{0.05}=2.3\right)$. Gene and Stephens expressed more whiteheads than Madsen and Rohde; 23.0, 20.2, 1.7 , and $1.4 \%$, respectively; $\mathrm{LSD}_{0.05}=3.1$. The significant interaction indicated that the date of planting was an important determinant of whitehead expression for only two of the four cultivars (Table 2). Percentage whiteheads for Gene and Stephens were greatest for the 20 September planting and much lower for plantings in October and November (Table 2). Mean percentages of whiteheads on Madsen and Rohde did not exceed $4 \%$ for any planting date.

Lesion occurrence and whitehead expression were not significantly correlated when cultivars were grouped and evaluated over individual planting dates. When data were evaluated for individual cultivars and planting dates, the only significant $(P<0.05)$ correlation occurred with Gene planted on 20 September.

Percentage whiteheads was never significantly correlated $(P<$ 0.10 ) with grain yield or test weight (data not presented).

Whitehead sampling date for commercial winter wheat cultivars. Precipitation was less than the 20-year mean during both years. Overall, the second year (2001-2002 crop year) was particularly dry but had sufficient late-season rainfall to provide adequate kernel maturation (Table 1).

During the 2000-2001 crop year, subcrown internode percentages were affected by inoculum $(P<0.0001)$ but not cultivar or the cultivar $\times$ inoculum interaction $(P>0.10)$. The mean percentages of

Table 2. Percentages of plants with subcrown internode lesions and prematurely ripening heads (whiteheads) due to Fusarium crown rot for four winter wheat cultivars planted on four dates at Pendleton and Moro, OR; standard errors of the means are also presented ${ }^{\mathrm{z}}$

\begin{tabular}{lcccc}
\hline & \multicolumn{4}{c}{ Cultivar } \\
\cline { 2 - 5 } Planting date \\
during 1996 & Gene & Madsen & Rohde & Stephens \\
\hline & \multicolumn{4}{c}{$\%$ plants with lesions on subcrown internode } \\
3 September & $40.0 \pm 2.2 \mathrm{~b}$ & $51.0 \pm 1.5 \mathrm{a}$ & $30.5 \pm 1.7 \mathrm{a}$ & $36.8 \pm 2.9 \mathrm{a}$ \\
20 September & $56.5 \pm 3.2 \mathrm{a}$ & $41.5 \pm 2.3 \mathrm{~b}$ & $35.8 \pm 2.4 \mathrm{a}$ & $28.0 \pm 1.1 \mathrm{~b}$ \\
10 October & $17.8 \pm 2.3 \mathrm{c}$ & $27.5 \pm 1.4 \mathrm{c}$ & $29.0 \pm 1.8 \mathrm{a}$ & $27.8 \pm 1.1 \mathrm{~b}$ \\
1 November & $5.0 \pm 0.9 \mathrm{~d}$ & $1.8 \pm 0.9 \mathrm{~d}$ & $1.3 \pm 0.5 \mathrm{~b}$ & $5.0 \pm 1.4 \mathrm{c}$ \\
$P>\mathrm{F}$ & $<0.0001$ & $<0.0001$ & $<0.0001$ & $<0.0001$ \\
LSD $_{0.05}$ & 7.2 & 5.2 & 6.0 & 5.9 \\
& \multicolumn{4}{c}{$\%$ whiteheads } \\
3 September & $28.4 \pm 4.7 \mathrm{~b}$ & $2.7 \pm 0.4 \mathrm{a}$ & $2.5 \pm 0.4 \mathrm{a}$ & $28.5 \pm 2.3 \mathrm{~b}$ \\
20 September & $56.0 \pm 5.1 \mathrm{a}$ & $3.8 \pm 0.6 \mathrm{a}$ & $3.0 \pm 0.5 \mathrm{a}$ & $41.8 \pm 2.9 \mathrm{a}$ \\
10 October & $8.4 \pm 1.7 \mathrm{c}$ & $0.2 \pm 0.2 \mathrm{~b}$ & $0.1 \pm 0.1 \mathrm{~b}$ & $6.2 \pm 1.3 \mathrm{c}$ \\
1 November & $4.3 \pm 1.0 \mathrm{c}$ & $0.1 \pm 0.1 \mathrm{~b}$ & $0.1 \pm 0.1 \mathrm{~b}$ & $4.5 \pm 1.1 \mathrm{c}$ \\
$P>\mathrm{F}$ & $<0.0001$ & 0.0001 & 0.0001 & $<0.0001$ \\
LSD $_{0.05}$ & 11.2 & 1.2 & 0.9 & 5.5 \\
\hline
\end{tabular}

${ }^{\mathrm{z}}$ Means followed by the same letter within a column for each disease parameter did not differ at $P=0.05$ according to the Fisher's least significant difference test. lesions in inoculated and control plots were 44.0 and $0.1 \%$, respectively $\left(\mathrm{LSD}_{0.05}=5.5\right)$.

Browning of crown tissue differed among cultivars $(P=0.0003)$, inoculum treatments $(P<0.0001)$, and the interaction of cultivar $\times$ inoculum $(P=0.0001)$. The mean percentages of browned crowns in inoculated and control plots were 40.4 and $0.8 \%$, respectively $\left(\mathrm{LSD}_{0.05}=4.4\right)$. The percentage of brown crowns among cultivars varied from 12.5 to $66.0 \%$ in inoculated plots and from 0 to $3.8 \%$ in noninoculated plots. The interaction was presumed to be significant because crown browning in the cultivar Bruehl was lowest among cultivars in the inoculated treatment and highest among cultivars in the noninoculated treatment.

A small number of whiteheads became visible in inoculated plots of the winter durum cv. 'Connie' on 10 June 2001. Counts of whiteheads and total heads in two rows of all replicates of the 20 cultivars were made on 15 June, and whitehead counts in the same rows were repeated at 2-day intervals until 3 July, at which time maturation of all cultivars made it impossible to continue. Fewer than $1 \%$ whiteheads were expressed in noninoculated plots (data not reported).

Whitehead expression for nine representative cultivars in inoculated plots during 2001 is shown in Figure 2 (top). Whitehead percentage was greatest in durum wheat cv. Connie (11.4\%), was never expressed in the triticale cv. 'Alzo', and was intermediate $(0.6-5.7 \%)$ for the 18 cultivars in the soft white wheat market class. The first evidence of whiteheads and the rate of increase to a maximum percentage (Fig. 2, bottom) varied among wheat cultivars.
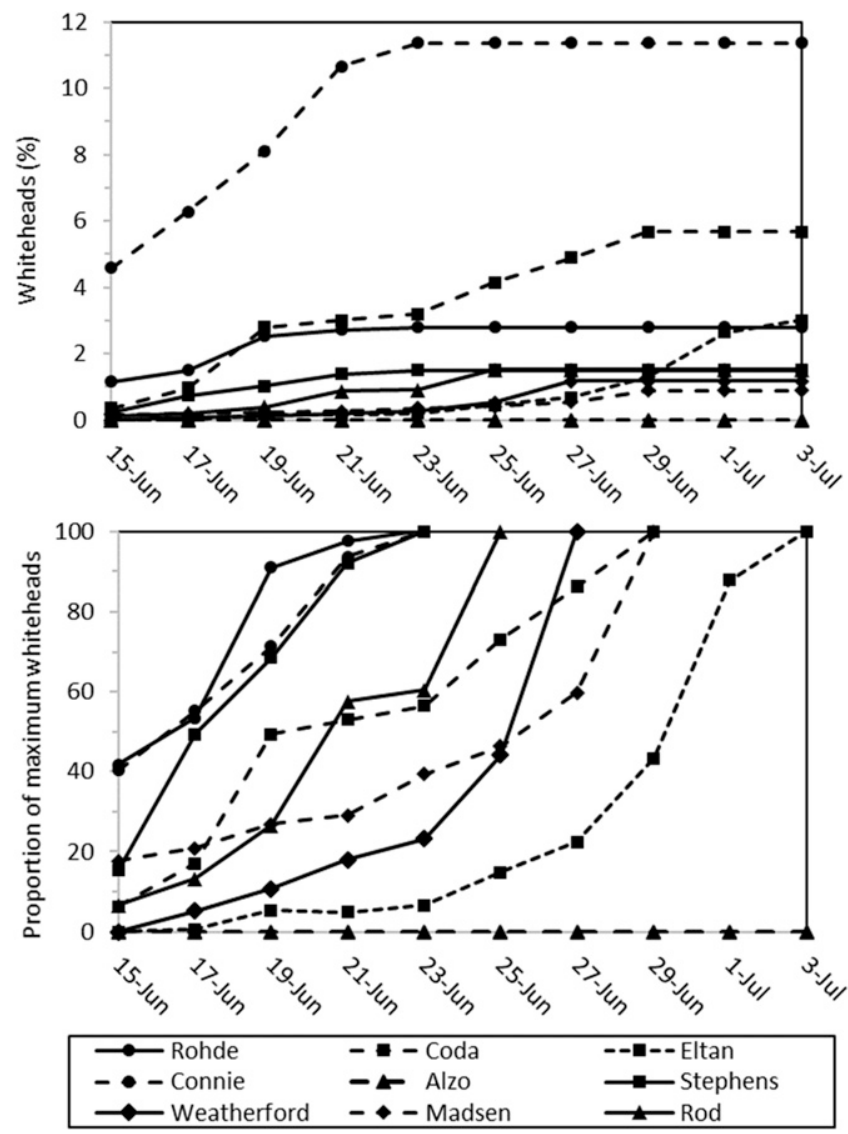

Fig. 2. Percentage of whiteheads on successive counting dates during 2001 for nine contrasting commercial winter wheat cultivars near Pendleton, OR, with whitehead counts expressed as the percentage of total heads on each count date (top) or as the proportion of the maximum percentage of whiteheads that would ultimately be formed (bottom). Whiteheads resulted from inoculation of soil with a mixture of five isolates of Fusarium pseudograminearum. Whiteheads were quantified at 2-day intervals starting 5 days after whiteheads first became evident in cv. Connie. When whiteheads in a specific cultivar were no longer countable due to stand maturation, the maximum percentage expressed at the last counting date was held constant for subsequent counting dates. 
The time interval from first detection to maximum expression of whiteheads occurred in as few as 5 to 6 days for cultivars such as Rohde, Weatherford, and several others not shown in Figure 2. Full expression of whiteheads on those cultivars occurred on or before 23 June, while stems and heads of other cultivars remained relatively green. In contrast, percentages of whiteheads increased steadily over periods of 12 to 14 days for Connie (10 to 23 June), Rod (15 to 25 June), Coda (17 to 29 June), and Eltan (19 June to 3 July). Four cultivars ('Bruehl', 'Lewjain', 'Eltan', and 'Dusty') were very slow to express whiteheads, with the maxima being attained on the last counting date ( 3 July). For Lewjain only, the late maturation was attributed to a low plant density caused by diminished seedling emergence and stand density (data not presented). Other cultivars had near complete seedling emergence and plant densities.

All wheat cultivars in the inoculated treatment contained whiteheads on 19 June 2001. The effects of inoculum, cultivar, and cultivar $\times$ inoculum interaction for that date were each significant at $P<$ 0.0001 . Mean whitehead expression for inoculated and control plots was $1.1 \%$ and $0 \%$, respectively $\left(\mathrm{LSD}_{0.05}=0.1\right)$. Cultivars in the trial were distinguished as five statistically separate groups. If counts had been made only on that date, as is generally done in cultivar screening nurseries in the PNW, only three of 19 wheat cultivars (Lambert, Temple, and Rohde) would have provided whitehead counts within $25 \%$ of the maxima that were ultimately expressed for each cultivar. If counts were only made 4 days later, on 21 June, the whitehead counts would have been equivalent to the maximum for only two of 19 wheat cultivars; Brundage and Temple.

Ten of 19 wheat cultivars reached the maximum percentage of whiteheads by 23 June 2001 . The treatment effects and interaction were significant at $P<0.0001$, and the cultivars could be distinguished as six statistically separate groups. However, two cultivars (Eltan and Dusty) expressed less than $8 \%$ of the maximum percentage of whiteheads ultimately observed for those cultivars, and six other cultivars expressed from 25 to $60 \%$ of their maxima. Also, if a single whitehead count had been made after 23 June, whiteheads would have been impossible to distinguish from apparently healthy heads for some cultivars.

Lesions on subcrown internodes were significantly correlated $(P=$ 0.0132 ) with percentages of browned crowns in the inoculated treatment. Neither of those two measures of crown rot were significantly correlated $(P>0.10)$ with the percentage of whiteheads in either inoculum treatment or for any date of whitehead count. Likewise, lesions and brown crowns were never significantly correlated with grain yield or test weight. Whiteheads were also never significantly correlated with grain test weight. In the inoculated treatment, whiteheads counted on all except the first date (15 June) were negatively correlated with grain yield; $P<0.0001, \mathrm{R}^{2}$ values from 0.32 to 0.38 . Whiteheads counted on the first two dates (15 and 17 June) in noninoculated plots were also negatively correlated with grain yield; $P<0.05 ; \mathrm{R}^{2}=0.09$ and 0.15 .

During the second year (2001-2002), subcrown internode percentages were affected by cultivar $(P=0.0054)$ but not inoculation or the cultivar $\times$ inoculum interaction $(P>0.10)$. The range of percentages among cultivars was from 0 to $55 \%$ in noninoculated controls and from 12 to $73 \%$ in the inoculated treatment. Mean percentages of lesions in control and inoculated plots were 30.0 and $37.7 \%$.

Browning of crown tissue differed among inoculum treatments $(P=0.0374)$ but not among cultivars or the interaction of cultivar $\times$ inoculum. 1.3 and $0.2 \%$, respectively $\left(\mathrm{LSD}_{0.05}=1.0\right)$. Only six of 20 cultivars had browned crowns in the inoculated plots, and the range among those six cultivars varied from 2.5 to $7.5 \%$.

Whiteheads were present and were counted on all cultivars on 30 June 2002. The counts were repeated on 3 July, and whiteheads could not be distinguished after that time. Percentage whiteheads on both sampling dates were significantly affected by inoculation $(P<$ $0.05)$, cultivar $(P<0.0001)$, and the cultivar $\times$ inoculum interaction $(P<0.0003)$. Mean percentages of whiteheads during both counting dates were less than $1 \%$ in noninoculated plots and less than $4.0 \%$ in inoculated plots; $\mathrm{LSD}_{0.05}=2.6$ and 2.1 for the first and second dates, respectively. In the inoculated and control treatments, the counts for
18 of 20 entries were essentially identical on both counting dates (data not shown). However, over the 4-day period, the counts for $\mathrm{Co}$ da increased from 0.3 to $2.3 \%$ in the control treatment and from 2.0 to $9.7 \%$ in the inoculated treatment. Counts for Dusty increased from 0.3 to $1.3 \%$ in the control treatment and from 5.7 to $18.2 \%$ in the inoculated treatment. Whitehead expression would have been poorly represented for those two cultivars if the counts had been made only on 30 June.

Lesions on subcrown internodes were never significantly correlated with percentages of browned crowns or whiteheads in either inoculum treatment. Likewise, lesions and brown crowns were never significantly correlated with grain yield or test weight. However, whiteheads on both dates were negatively correlated with grain yield $\left(P<0.0001 ; \mathrm{R}^{2}=0.17\right.$ and 0.19$)$. Whiteheads in noninoculated plots were not significantly correlated $(P<0.07)$ with grain yield during either year.

Whitehead sampling date for winter wheat breeding lines. During the 2001-2002 crop year, with 50 wheat entries planted at Pendleton, percentages of lesions on subcrown internodes were affected by inoculum $(P<0.0001)$, cultivar $(P=0.07)$, and a cultivar $\times$ inoculum interaction $(P=0.05)$. The mean percentages of lesions in inoculated and control plots were 46.9 and $11.4 \%$, respectively $\left(\mathrm{LSD}_{0.05}=4.6\right)$. The percentages of lesions among the 50 entries ranged from 0 to $100 \%$ in inoculated plots and from 0 to $70 \%$ in noninoculated controls.

Whitehead counts were made on 29 June and 3 July 2002. Counts for 43 of 50 entries were identical on both sampling dates (data not shown). Two entries exhibited higher percentages of whiteheads during the second counting date in both the control and inoculated treatment. Over the 5-day interval, counts for OR943560 increased from 0 to $0.7 \%$ in the control treatment and from 0.6 to $1.3 \%$ in the inoculated treatment. These counts were low and unlikely to be of biological importance. However, counts for ORD948927 increased from 1.8 to $2.5 \%$ in the control treatment and from 4.0 to $6.7 \%$ in the inoculated treatment. The potential for whiteheads to form on that cultivar would have been erroneously low if counts had been made only on 29 June.

Whiteheads were not significantly correlated $(P>0.80)$ with subcrown internode lesions in either the inoculum or control treatment. In the inoculated treatment, whiteheads and grain yield were negatively correlated $(P=0.002, n=50)$, albeit the association was considered biologically unimportant with a regression coefficient of $\mathrm{R}^{2}=$ 0.008 .

The 2002-2003 crop year at Moro was drier than normal and had an exceptionally dry finish to the growing season (Table 1). For the 100 wheat entries planted at Moro, percentages of lesions on subcrown internodes were affected by inoculum $(P<0.0001)$ and culti$\operatorname{var}(P=0.02)$ but not by a cultivar $\times$ inoculum interaction $(P=0.18)$. The mean percentages of lesions in inoculated and control plots were 62.4 and $46.3 \%$, respectively $\left(\mathrm{LSD}_{0.05}=3.6\right.$ ). The percentages of lesions among the 100 wheat entries ranged from 10 to $100 \%$ in inoculated plots and from 0 to $100 \%$ in noninoculated controls.

Severity of subcrown internode lesions was affected both by inoculum $(P<0.0001)$ and cultivar $(P<0.0001)$ but not by a cultivar $\times$ inoculum interaction $(P=0.08)$. The mean percentages of lesions in inoculated and control plots were 2.1 and $1.4 \%$, respectively $\left(\mathrm{LSD}_{0.05}=0.1\right)$. The range of severities among the 100 wheat entries was from 1 to 4 in inoculated plots and from 0 to 4 in noninoculated controls.

The percentage of plants with browned crown tissue during early spring was affected by inoculum $(P<0.0001)$ but not cultivar $(P=$ $0.09)$ or cultivar $\times$ inoculum interaction $(P=0.13)$. The mean percentages of affected crowns in inoculated and control plots were 7.5 and $0.6 \%$, respectively $\left(\mathrm{LSD}_{0.05}=1.3\right.$ ). Percentages of browned crowns ranged from 0 to $100 \%$ in inoculated plots and from 0 to $90 \%$ in noninoculated controls.

At least a few whiteheads were visible in one or more replicates for all of the 100 noninoculated entries on the first counting date (13 June 2003). The percentages of whiteheads were affected $(P<0.0001)$ by inoculum, cultivar, and cultivar $\times$ inoculum interaction. The mean 
percentage of whiteheads was $13.3 \%$ in the inoculated entries and $2.4 \%$ in the noninoculated entries $\left(\mathrm{LSD}_{0.05}=1.0\right.$; Table 3$)$. These percentages increased during the 4-day interval from 13 to 17 June, after which 66 entries could no longer be counted due to maturation. A group of 34 late-maturing cultivars were counted again on 19 June. In that subset, whiteheads in the controls did not increase significantly over the 4-day interval from 13 to 17 June, but did increase over the 2-day interval from 17 to 19 June (Table 3). As noted previously, the winter durum cultivar Connie exhibited far more whiteheads than other wheat cultivars. The whitehead counts for Connie were 21,53 , and $95 \%$ in the control treatment on 13,17 , and 19 June, and were 76 and $95 \%$ in the inoculated treatment on 13 and 17 June, respectively. In the noninoculated control, no other cultivar exceeded $17 \%$ whiteheads on 17 June or $27 \%$ on 19 June. Likewise, in the inoculated treatment on 13 and 17 June, no cultivar except Connie exceeded 56 and $62 \%$ whiteheads on those respective dates. Over the 4-day interval between the first and second counting dates, the increase in percentage of whiteheads for 100 individual cultivars varied from 0.2 to $6.6 \%$ in the controls and from 0.2 to $18.4 \%$ in the inoculated treatment. Over the 2-day interval between the second and third counting dates, the increase in percentage of whiteheads for 34 individual cultivars varied from 0.5 to $25.3 \%$ in the controls and from 3.5 to $35.9 \%$ in the inoculated treatment. Disparities in the date on which a maximum expression of whiteheads occurred for individual cultivars in this trial would have provided very different ratings for most cultivars if they had been rated only once.

Three representative commercial cultivars were selected to evaluate trends for standard error of the means for whiteheads in inoculated plots on the three counting dates during 2003. A high level of variability among replicates was observed for each cultivar. Means, standard errors, and ranges for three replicates increased with each successive counting date. For cultivar Bruehl, these values on three sequential sampling dates were $5.8 \% \pm 2.5$ (range of $0-10.3 \%$ ), $20.7 \% \pm 6.0(7.5-35.7 \%)$, and $33.2 \% \pm 9.3(16.4-59.5 \%)$. Corresponding values for Coda were $8.3 \% \pm 1.8(3.9-12.3 \%), 20.7 \% \pm$ $6.6(5.0-37.0 \%)$, and $39.2 \% \pm 10.2(22.0-68.0 \%)$. Values for Lambert were $12.5 \% \pm 2.0(8.7-16.4 \%), 21.0 \% \pm 5.0(6.6-29.8 \%)$, and $33.8 \% \pm 11.5(10.3-62.3 \%)$.

Grain yield during 2003 was affected by inoculum $(P<0.0001)$, cultivar $(P<0.0001)$, and a cultivar $\times$ inoculum interaction $(P=$ $0.0018)$. The mean yields in inoculated and control plots were 3,519 and $3,652 \mathrm{~kg} / \mathrm{ha}$, respectively $\left(\mathrm{LSD}_{0.05}=19.7\right)$. Grain test weight was similarly affected at equal $P$ values for each factor and their interaction. Test weights in inoculated and control plots were 672 and $697 \mathrm{~g} /$ liter, respectively $\left(\mathrm{LSD}_{0.05}=3.7\right)$.

In inoculated and control treatments during the 2002-2003 crop year, lesion severity on subcrown internodes was not closely associated with incidence of lesions $\left(P<0.0001, \mathrm{R}^{2}<0.06\right)$, infected crowns $\left(P<0.03, \mathrm{R}^{2}<0.01\right)$, whiteheads on any sampling date $(P>0.10)$, grain yield $(P>0.30)$, or grain test weight $(P>0.40)$. The incidence of lesions in inoculated and noninoculated treatments was also not well correlated with infected crowns $\left(P<0.001, \mathrm{R}^{2}=\right.$ 0.03 and 0.09 , respectively), whiteheads on any sampling date

Table 3. Percentages of whiteheads and standard error of the means for elite winter wheat breeding lines inoculated with a mixture of five isolates of Fusarium pseudograminearum or not inoculated (control) at Moro during the 2002-2003 crop year; 100 cultivars were counted on 13 and 17 June 2003, and a 34-cultivar late maturing subset of the 100 entries remained countable on 19 June $^{\mathrm{z}}$

\begin{tabular}{lccccccc}
\hline & \multicolumn{3}{c}{ Control } & & \multicolumn{3}{c}{ Inoculated } \\
\cline { 2 - 3 } \cline { 6 - 8 } & 13 June & 17 June & 19 June & & 13 June & 17 June & 19 June \\
\hline 100 entries counted on two dates & & & & & \\
Mean & $2.4 \pm 0.3 \mathrm{~d}$ & $6.1 \pm 0.6 \mathrm{c}$ & - & & $13.3 \pm 1.1 \mathrm{~b}$ & $25.2 \pm 1.3 \mathrm{a}$ & - \\
Range & $0-21.5$ & $0.9-53.0$ & - & & $0.9-76.3$ & $1.7-95.0$ & - \\
34 late-maturing entries counted on three dates & & & \\
Mean & $1.6 \pm 0.3 \mathrm{~d}$ & $4.0 \pm 0.4 \mathrm{~d}$ & $10.3 \pm 1.0 \mathrm{c}$ & & $8.5 \pm 1.4 \mathrm{c}$ & $16.1 \pm 1.4 \mathrm{~b}$ & $29.1 \pm 1.9 \mathrm{a}$ \\
Range & $0.0-9.6$ & $0.9-10.5$ & $1.1-26.3$ & & $0.9-48.0$ & $1.7-48.3$ & $4.8-61.6$ \\
\hline
\end{tabular}

${ }^{\mathrm{z}}$ Means followed by the same letter within a row did not differ at $P=0.05$ according to the Fisher's least significant difference test.
$(P>0.15)$, grain yield $(P>0.40)$, or grain test weight $(P>0.40)$. Similarly, there were no significant associations between percentages of browned crowns and whiteheads, grain yield, or grain test weight. Grain yield and test weight in inoculated and control treatments were not significantly correlated with percentages of whiteheads during any of the three whitehead counting dates. Regression lines for yield in inoculated and control treatments were horizontal across the full range of whitehead percentages on each of three counting dates, as illustrated in Figure 3 for the second counting date in inoculated plots during 2003.

Heading date for winter wheat cultivars. Relationships between cultivar heading date and expression of whiteheads during a single counting date were evaluated for data from eight replicated cultivar screening trials over a period of 4 years near Moro. Data were from the Oregon Soft White Winter Wheat Elite Yield Trial (OWEYT) and Oregon Hard Winter Wheat Elite Yield Trial (HWEYT) during the years 2014-2017. The crop harvested during 2015 experienced a particularly dry spring and early summer (Table 1 ).

Whiteheads were counted on 18 June 2015, 16 June 2016, and 28 June 2017. The percentage whitehead mean and range, and number of cultivars evaluated for OWEYT varied during 2014 (8.2, 1.817.5, 42), 2015 (16.4, 3.8-47.5, 22), 2016 (4.7, 0.5-12.5, 39), and 2017 (24.8, 6.5-48.8, 29). Similar variability occurred for HWEYT during 2014 (16.1, 1.1-45.5, 25), 2015 (12.0, 2.5-21.3, 12), 2016 (4.8, 2.0-8.8, 29), and $2017(31.4,11.8-63.0,17)$. Regressions of heading date and $\log$ of the percentage whiteheads were significant $(P<0.10)$ for four of eight nurseries evaluated (Fig. 4). These correlations indicated that the highest percentages of whiteheads occurred on cultivars that headed earliest. However, since half the nurseries failed to exhibit a significant relationship, it is likely that the association shown in Figure 4 is variable. This is particularly important since only one of the two trials conducted at adjacent sites showed significant associations during 2014 and 2015, whereas neither nursery had significant associations during 2016 and both nurseries had significant associations during 2017. Drought reduced yield in nurseries during 2015 but not during 2014, 2016, or 2017. There were no apparent patterns in these data or in the weather that explained why the association was significant in only half the trials.

There were significant correlations between percentage whiteheads and grain yield for three of seven nurseries; 2014 OWEYT, 2014 HWEYT, and 2015 OWEYT. A lack of harvest data prevented this relationship from being evaluated for one nursery (2017 HWEYT). Figure 5 illustrates the two most significant associations (2014 OWEYT and 2014 HWEYT) detected among three nurseries where significant associations were found. In the other nursery (2015 OWEYT), the regression coefficient was much lower $\left(\mathrm{R}^{2}=0.0783\right)$, indicating a higher level of variability among individual cultivars, which was also observed in nurseries in which these associations were not significant. The 2014 OWEYT nursery had a broad range of grain yields $(3,459$ to $5,887 \mathrm{~kg} / \mathrm{ha})$ and a narrow range of whiteheads (1.8-17.5\%). The 2014 HWEYT nursery had a narrow range

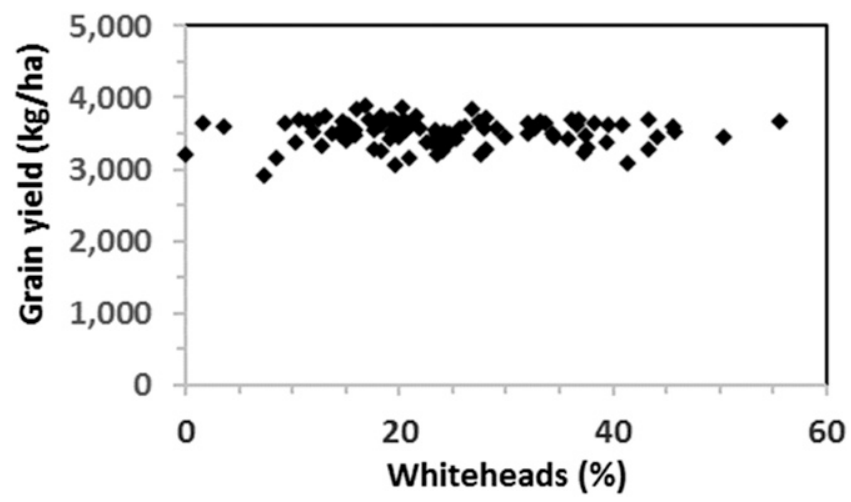

Fig. 3. Lack of association between percentage of whiteheads and grain yield for 100 wheat lines in plots inoculated with Fusarium pseudograminearum near Moro, OR during the 2002-2003 crop year. 
of grain yields (1,537 to $2,165 \mathrm{~kg} / \mathrm{ha})$ and a broader range of whiteheads (1.1-45.5\%). The 2015 OWEYT nursery had broad ranges for both grain yields $(2,994$ to $5,516 \mathrm{~kg} / \mathrm{ha})$ and whiteheads $(3.8-52.5 \%)$. The four nurseries for which the correlation was not statistically significant $(P>0.25)$ had trend lines that were either horizontal (2016 HWEYT), slightly positive (2015 HWEYT and 2017 OWEYT), or slightly negative (2016 OWEYT).

\section{Discussion}

Whitehead counts are the most commonly reported estimate of Fusarium crown rot severity on wheat in Pacific Northwest field trials. Whitehead counts are rapid and inexpensive, and the quantification of stem browning requires much additional expense for labor and a much greater amount of time before labor becomes available to assess that symptom on saved samples of stubble collected after plots are harvested. An important finding from these studies was that the manner in which whiteheads are quantified clearly affected the way those counts could be interpreted. It is common in many agronomic studies to quantify whiteheads only once. This research showed that a single counting date in cultivar screening trials could provide unreliable estimates of crown rot susceptibility. Some cultivars expressed whiteheads early, and the percentages did not change when counts were made at 2-day intervals. Other cultivars continued to express increasing percentages of whiteheads until counts were no longer possible due to crop maturation. A contributor to that variability among cultivars was the maturation pattern for individual cultivars, as indicated by the heading date. There was a clear tendency for whitehead counts in at least some studies to be highest in the earliest-maturing cultivars included within individual screening nurseries. This variability should be considered wherever whiteheads are used to compare crown rot susceptibilities among cultivars. Moreover, whitehead counts made on a single date should not continue to be released to farmers and extensionists as an indicator of cultivar susceptibility to this disease.

Additionally, different isolates of both $F$. pseudograminearum and $F$. culmorum caused variable timings in the expression of whiteheads on spring wheat. It is anticipated that the same would be true for winter wheat. It has been established that populations of Fusarium species that cause crown rot are highly variable in the PNW (Poole et al. 2013; Smiley and Patterson 1996) and overseas (Cumagun and Miedaner 2003; Liddell 1985; Miedaner et al. 2001;
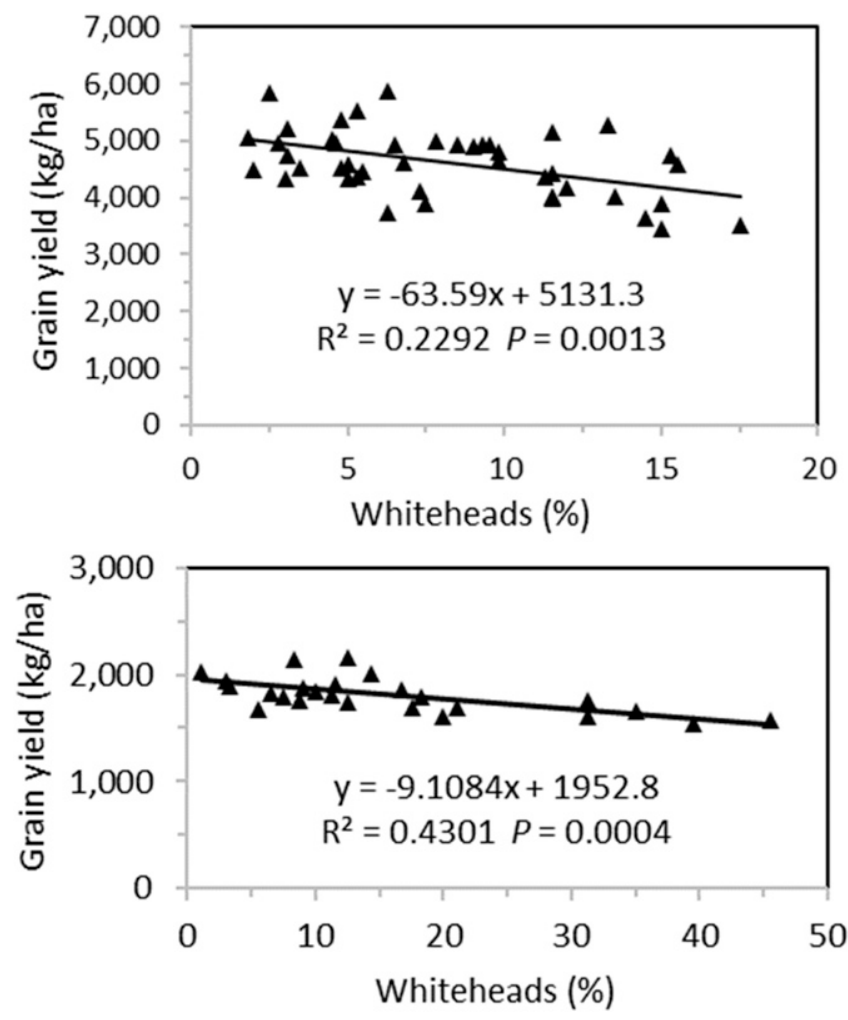

Fig. 5. Associations between percentage of whiteheads and grain yield for cultivars in trials near Moro, OR during a drought year: top: 2014 Oregon Soft White Winter Wheat Elite Yield Trial, bottom: 2014 Oregon Hard Wheat Elite Yield Trial.
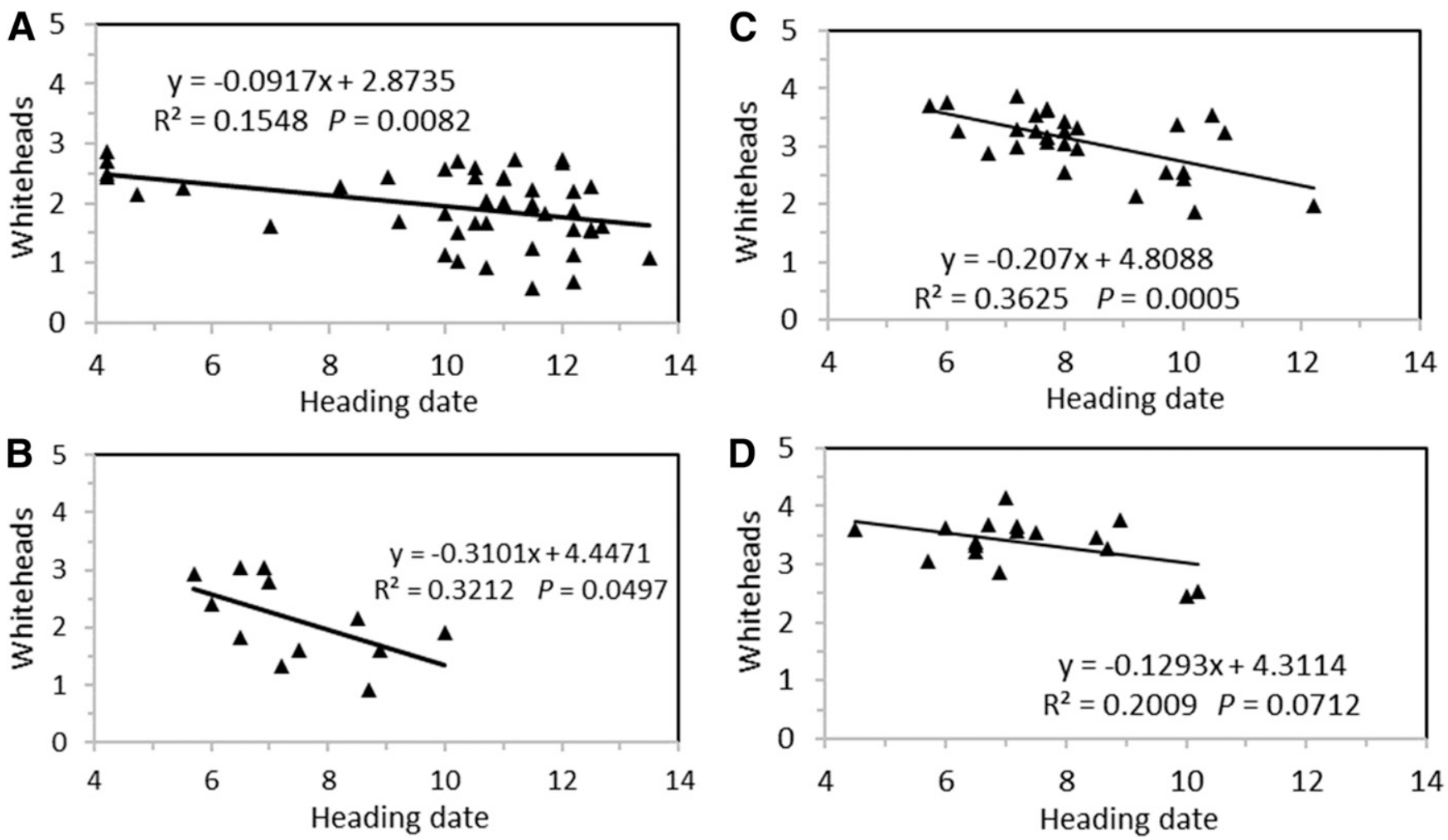

Fig. 4. Relationship between natural logarithm of percentage whiteheads and date of heading (days relative to cultivar Bobtail, plus 10 days) near Moro, OR: (A) 2014 Oregon Soft White Winter Wheat Elite Yield Trial, (B) 2015 Oregon Hard Winter Wheat Elite Yield Trial, (C) 2017 Oregon Soft White Winter Wheat Elite Yield Trial, and (D) 2017 Oregon Hard Winter Wheat Elite Yield Trial. 
Pouzeshimiab et al. 2016). As has also been established, the experiment reported here confirmed that the most aggressive isolates of $F$. pseudograminearum tend to be more aggressive than the most aggressive isolates of $F$. culmorum, although much variability occurs among isolates of both species (Barry et al. 2018; Knight and Sutherland 2017; Liddell 1985; Poole et al. 2013; Saad et al. 2018; Smiley and Patterson 1996). Results of this experimentation also suggested the presence of spatial variability of native inoculum within trials, making it important to conduct side-by-side comparisons of the same cultivar in inoculated and noninoculated plots. For instance, there was a clear indication in this research that an increase in whiteheads within an inoculated strip of plants in the spring wheat experiment was occurring mostly in response to a higher-than-expected effect from native inoculum in those rows within the trial. Comparisons of crown rot caused by individual isolates in close association with plants affected by the native population of Fusarium was therefore important for making a more precise estimate of aggressiveness for individual isolates under field conditions in regions where these pathogens are ubiquitous.

Purss (1966) and Knight et al. (2017) demonstrated that F. pseudograminearum could colonize stems of wheat without causing visual symptoms such as browning of basal internodes or occurrence of whiteheads. Knight et al. further demonstrated that when heads became prematurely senesced (whiteheads), there was a much greater colonization of vascular tissue by Fusarium compared with stems on which the heads senesced normally. After the pathogen invaded the root or crown tissue, the xylem in the basal internodes was the first and most frequent tissue to become colonized. After colonizing the xylem, the pathogen moved more fully into the phloem of stems that produced whiteheads. Knight et al. therefore suggested that the pathogen was likely involved in disruption of sugar flow in stems with whiteheads, as well as disruption of water flow in stems with and without whiteheads. Knight et al. concluded that the determining factor for whether a wheat head senesced naturally or prematurely may be associated with the proportion of vascular bundles that become colonized by the pathogen. Their observations showed differences between the two cultivars studied, supporting observations that the progress of disease in the basal internodes and the expression of whiteheads may vary individually in response to variables of cultivar, pathogen species, pathogen isolate virulence, and environment. Knight and Sutherland (2015) also showed that browning of the basal internodes was more significantly correlated with the mass of fungal mycelium in those culms when the measurements were made at a time when plants were in the anthesis growth stage rather than later measurements at the time of harvest. Most reports of culm browning in the United States have been based upon stem samples collected after wheat grain was harvested.

Percentages of whiteheads were seldom correlated with other measures of crown rot. In particular, whiteheads were seldom significantly correlated with incidence and severity of lesions on subcrown internodes, or of the visual rotting of crown tissue. These results reinforce previous alerts regarding this issue. Burgess et al. (2001) succinctly stated that his lifelong research in Australia indicated that "The proportion of whiteheads is not a reliable parameter for evaluation of [crown rot] tolerance in unprotected field plots as their formation is dependent on moisture stress and higher temperatures." Smiley et al. (2005b) reiterated that conclusion from work in the PNW, concluding that "low numbers of whiteheads in wheat crops in higher precipitation zones may be incorrectly interpreted to mean that crown rot is not significantly affecting yield ..." More recently, using modern technologies, Hollaway et al. (2013) reported that DNA of $F$. pseudograminearum in soil before planting is generally more highly correlated with measures of brown internodes on culms than of whiteheads. There are different influences of environmental factors that affect initial infection and development of earlyseason symptoms and factors that affect the formation of whiteheads at the end of the season. Research reported here demonstrated that the common visible symptoms of crown rot are not closely related. Since each symptom type has been used to report crown rot incidence or severity in the PNW, it is recommended that future reports be restricted to measures of crown rot that are apparently more closely associated with grain yield, such as the prevalence and extent of browning of basal internodes or pathogen DNA biomass inside wheat stems (Barry et al. 2018; Dyer et al. 2009; Forknall et al. 2018a, 2018b; Hogg et al. 2007; Knight and Sutherland 2013, 2015, 2016, 2017; Saad et al. 2018).

Expression of whiteheads was also highly variable across replicates. Large numbers of replicates would be required to reduce the standard error of means for treatments. Smiley and Yan (2009) previously reported that very high numbers of observations were required to provide rankings of cultivar susceptibilities at the $95 \%$ level of confidence.

Cultivars varied greatly with respect to the timing of whitehead expression. Reasons for that variability are poorly defined. Heading date appeared to be a contributing factor, but it has also been demonstrated that genetic variability exists with respect to the capacity of $F$. culmorum and $F$. pseudograminearum to colonize the subcrown internode and lower culm tissues (Barry et al. 2018; Knight et al. 2017; Saad et al. 2018). Wheat cultivars also respond differently to increasing levels of crown rot inoculum, and this relationship varies across experimental locations (Barry et al. 2018; Forknall et al. 2018a, 2018b). Some durum wheat cultivars are particularly susceptible to attack by these Fusarium species (Hogg et al. 2007; Hollaway et al. 2013; Kirkegaard et al. 2004; Southwell et al. 2003). In the current field trials, the winter durum cultivar Connie was much more susceptible than the soft white and hard red wheat cultivars. It was also noted that the triticale cultivar Alzo exhibited no whiteheads over two years of testing.

Whiteheads were negatively correlated with wheat yield in several comparisons during the course of this research. However, the significance of the correlation was generally quite variable over years and sometimes depended on the date on which the whiteheads were counted. In most cases, even with a highly significant correlation, the regression coefficient for this relationship was quite low, indicating the need for caution when interpreting the results. Smiley et al. (2005b) previously reported field trials in which yields were suppressed $12 \%$ by application of inoculum identical to that applied in experiments reported here. They noted that the precipitation during those trials was higher than normal, and that the reductions in yield occurred "without notable increases in occurrences of whiteheads" above those caused by the native population. In one trial reported for the current study, thinning of plant stands due to poor emergence enabled infected plants to mature without expression of whiteheads. These examples support and reiterate that it is possible for crown rot to affect wheat crops without producing whiteheads (Burgess et al. 2001; Knight et al. 2017; Smiley et al. 2005b).

Whiteheads were never significantly correlated with grain test weight. The converse might be predicted since test weight is dramatically reduced in stems that produce whiteheads (Smiley and Patterson 1996; Smiley et al. 2005b). This apparent anomaly is likely related to the fact that shriveled grains, which are very light in weight, are likely to have been blown out of the grain stream by the fan inside the combine that separated and removed the chaff. As such, many or most shriveled kernels from the whiteheads in these combine-harvested experiments were probably not collected in the grain that was used to measure grain yield and test weight.

It has been known for at least four decades that the severity of Fusarium crown rot is exacerbated by application of high rates of nitrogen fertilizer in semiarid environments (Cook 2017). For instance, Smiley et al. (1996) showed that the percentage of whiteheads in a single winter wheat cultivar was increased as the rate of nitrogen application was increased in $45 \mathrm{~kg} / \mathrm{ha}$ increments, from 0 to $180 \mathrm{~kg} \mathrm{~N} / \mathrm{ha}$, under three different tillage systems. However, the full seasonal complement of nitrogen in almost all of the earlier research was applied by shanking anhydrous ammonia or aqua ammonia into fallow before the winter wheat was planted. Top-dressing nitrogen into standing wheat crops is seldom practiced in the inland PNW because there is generally insufficient rainfall to move the nutrients downward to a depth where they can be absorbed by roots. Improvements in fertilizer 
application equipment technology now makes it possible to dispense fertilizer into soil at any time during all early-plant growth stages. This research compared applications of fertilizer before planting (shanked into fallow), at the time of planting (injected by spoke-wheel injector), or into stands of young wheat plants during early spring (spoke-wheel injector). The results provided support for previous reports that higher nitrogen rates increase the incidence and severity of whiteheads. However, the impact of nitrogen on expression of whiteheads was associated with the total amount of nitrogen applied and not with the timing of the application. The percentage of whiteheads was comparable when the fertilizer was applied fully or in part at the various timing intervals.

The expression of whiteheads became strongly reduced as the planting date for winter wheat was moved from September to midOctober or later. There are several possible interacting factors that could have influenced this result. Winter wheat planted during early September in the PNW is planted deeply into warm, moist soil that lies below an over-burden of air-dry soil (Schillinger et al. 2006). This dust mulch or 'trashy' fallow system is accomplished with the use of a rod weeder and the dependence upon deep-furrow drills capable of planting seed deeply into moist soil while at the same time creating a furrow that allows the seedling to emerge through only a portion of the original overburden of soil. By late September, the soil at seeding depth typically becomes colder and the depth increases to reach moisture sufficient to germinate seed. In conventional tillage systems, there is a time when the deep-furrow drill is no longer able to plant seed into moist soil at a depth at which the coleoptile is capable of emerging, resulting in stand failure. After that time, conventional drills and all no-till drills, equipped with hoe- or disk-type openers, are used to plant seed more shallowly either into dry soil or soil recently moistened by rain. Soil at shallow depths nearly always becomes cold and wet by early November in the PNW. The Fusarium pathogens involved in crown rot are more infective when soils are moist $(-0.3$ to $-0.6 \mathrm{MPa})$ rather than wet or very dry (Burgess et al. 2001). The initial site of pathogen invasion (subcrown internode versus basal stem or crown), and possibly the rate of disease progress, is also influenced by the depth of planting with respect to the depth of inoculum (incorporated by tillage, or on or near the soil surface) (Summerell et al. 1989, 1990). Beddis and Burgess (1992) demonstrated that infection occurs uniformly under a range of soil moisture conditions and the rate of disease increase is then heavily dependent upon moisture stress imposed upon the plant. Poorly defined interactions of moisture, temperature, and planting depth under field experimental conditions are likely to have influenced the decline of whitehead percentages as planting dates were delayed in this research.

\section{Literature Cited}

Baker, J. L., Colvin, T. S., Marley, S. J., and Dawelbeit, M. 1989. A point-injector applicator to improve fertilizer management. J. Appl. Eng. Agric. 5:334-338.

Barry, J., Percy, C., Knight, N., and Sutherland, M. 2018. Comparison of the growth patterns of two crown rot causing pathogens in bread wheat. Pages 9-10 in: Proc. 10th Australas. Soilborne Dis. Symp. V. Gupta and B. Hall, eds. Adelaide, Australia, Online at, https://www.appsnet.org/publications/ proceedings/ASDS $\% 202018 \% 20$ Proceedings.pdf

Beccari, G., Covarelli, L., and Nicholson, P. 2011. Infection processes and soft wheat response to root rot and crown rot caused by Fusarium culmorum. Plant Pathol. 60:671-684.

Beddis, A. L., and Burgess, L. W. 1992. The influence of plant water stress on infection and colonization of wheat seedlings by Fusarium graminearum Group 1. Phytopathology 82:78-83.

Burgess, L. W., Backhouse, D., Summerell, B. A., and Swan, L. J. 2001. Crown rot of wheat. Pages 271-294 in: Fusarium. B. A. Summerell, J. F. Leslie, D. Backhouse, W. L. Bryden, and L. W. Burgess, eds. APS Press, St. Paul, MN.

Chen, C., Payne, W. A., Smiley, R. W., and Stoltz, M. A. 2003. Yield and wateruse efficiency of eight wheat cultivars planted on seven dates in northeastern Oregon. Agron. J. 95:836-843.

Cook, R. J. 1968. Fusarium root and foot rot of cereals in the Pacific Northwest. Phytopathology 58:127-131.

Cook, R. J. 1980. Fusarium foot rot of wheat and its control in the Pacific Northwest. Plant Dis. 64:1061-1066.

Cook, R. J. 1981. Fusarium diseases of wheat and other small grains in North America. Pages 39-52 in: Fusarium: Diseases, Biology and Taxonomy. P. E.
Nelson, T. A. Toussoun, and R. J. Cook, eds. The Pennsylvania State Univ. Press, University Park, PA

Cook, R. J. 2017. Untold Stories; forty years of field research on root diseases of wheat. APS Press, St. Paul, MN.

Cumagun, C. J. R., and Miedaner, T. 2003. Aggressiveness of 42 isolates of Gibberella zeae (Fusarium graminearum) in wheat under field and greenhouse conditions. J. Plant Dis. Prot. 110:554-559.

Dodman, R. L., and Wildermuth, G. B. 1987. Inoculation methods for assessing resistance in wheat to crown rot caused by Fusarium graminearum Group 1. Aust. J. Agric. Res. 38:473-486

Dodman, R. L., Wildermuth, G. B., Klein, T. A., and Ellison, F. W. 1985. Field resistance of wheat cultivars to crown rot (Fusarium graminearum Group 1). Pages 167-168 in: Ecology and Management of Soilborne Plant Pathogens. C. A. Parker, A. D. Rovira, K. J. Moore, and P. T. W. Wong, eds. APS Press, St. Paul, MN.

Dyer, A. T., Johnston, R. H., Hogg, A. C., and Johnston, J. A. 2009. Comparison of pathogenicity of the Fusarium crown rot (FCR) complex (F. culmorum, $F$ pseudograminearum and $F$. graminearum) on hard red spring and durum wheat. Eur. J. Plant Pathol. 125:387-395.

Forknall, C., Simpfendorfer, S., and Kelly, A. 2018a. Using response curves to explore variation in the tolerance and resistance of wheat cultivars to crown rot across environments in the northern grains region of Australia. Pages 26-27 in: Proc. 10th Australas. Soilborne Dis. Symp. V. Gupta and B. Hall, eds. Adelaide, Australia, Online at, https://www.appsnet.org/publications/ proceedings/ASDS\%202018\%20Proceedings.pdf

Forknall, C., Simpfendorfer, S., and Kelly, A. 2018b. Multi-environment analysis to explore the responsiveness of northern region wheat varieties to crown rot. Pages 28-29 in: Proc. 10th Australas. Soilborne Dis. Symp. V. Gupta and B. Hall, eds. Adelaide, Australia, Online at, https://www.appsnet.org/publications/ proceedings/ASDS $\% 202018 \% 20$ Proceedings.pdf

Hogg, A. C., Johnson, R. H., and Dyer, A. T. 2007. Applying real-time quantitative PCR to Fusarium crown rot of wheat. Plant Dis. 91:1021-1028.

Hollaway, G. J., Evans, M. L., Wallwork, H., Dyson, C. B., and McKay, A. C 2013. Yield loss in cereals, caused by Fusarium culmorum and $F$. pseudograminearum, is related to fungal DNA in soil prior to planting, rainfall, and cereal type. Plant Dis. 97:977-982.

Hollaway, G. J., and Exell, G. K. 2010. Survey of wheat crops for white heads caused by crown rot in Victoria, 1997-2009. Australas. Plant Pathol. 39: 363-367.

Kirkegaard, J. A., Simpfendorfer, S., Holland, J., Bambach, R., Moore, K. J., and Rebetzke, G. J. 2004. Effect of previous crops on crown rot and yield of durum and bread wheat in northern NSW. Aust. J. Agric. Res. 55:321-334.

Klassen, J. A., Matthee, F. N., Marasas, W. F., and van Schalkwyk, D. J. 1992 Survey of Fusarium species associated with crowns of healthy-head and white-head wheat plants in the southern and western Cape Province. Phytophylactica 24:85-94

Klein, T. A., Burgess, L. W., and Ellison, F. W. 1991. The incidence and spatial patterns of wheat plants infested by Fusarium graminearum Group 1 and the effect of crown rot on yield. Aust. J. Agric. Res. 42:399-407.

Knight, N. L., Macdonald, B., and Sutherland, M. W. 2017. Colonization of durum wheat (Triticum turgidum L. var. durum) culms exhibiting premature senescence (dead heads) associated with Fusarium pseudograminearum crown rot. Plant Dis. 101:1788-1794.

Knight, N. L., and Sutherland, M. W. 2013. Spread of Fusarium pseudograminearum in wheat seedling tissues from a single inoculation point. Australas. Plant Pathol. 42:609-615.

Knight, N. L., and Sutherland, M. W. 2015. Culm discolouration as an indicator of Fusarium pseudograminearum biomass. Australas. Plant Pathol. 44:319-326.

Knight, N. L., and Sutherland, M. W. 2016. Histopathological assessment of Fusarium pseudograminearum colonization of cereal culms during crown rot infections. Plant Dis. 100:252-259.

Knight, N. L., and Sutherland, M. W. 2017. Assessment of Fusarium pseudograminearum and $F$. culmorum biomass in seedlings of potential host cereal species. Plant Dis. 101:2116-2122.

Liddell, C. M. 1985. The comparative pathogenicity of Fusarium graminearum Group 1, Fusarium culmorum and Fusarium crookwellense as crown, foot and root rot pathogens of wheat. Australas. Plant Pathol. 14:29-31.

Liu, X., and Liu, C. 2016. Effects of drought-stress on Fusarium crown rot development in barley. PLoS One 11:e0167304.

Miedaner, T., Schilling, A. G., and Geiger, H. H. 2001. Molecular genetic diversity and variation for aggressiveness in populations of Fusarium graminearum and Fusarium culmorum sampled from wheat fields in different countries. J. Phytopathol. 149:641-648.

Nelson, P. E., Toussoun, T. A., and Marasas, W. F. O. 1983. Fusarium species: An Illustrated Manual for Identification. The Pennsylvania State Univ. Press, University Park.

Papendick, R. I., and Cook, R. J. 1974. Plant water stress and development of Fusarium foot rot in wheat subjected to different cultural practices. Phytopathology 64:358-363.

Poole, G. J., Smiley, R. W., Walker, C., Huggins, D., Rupp, R., Abatzoglou, J., Garland-Campbell, K., and Paulitz, T. C. 2013. Effect of climate on the distribution of Fusarium spp. causing crown rot of wheat in the Pacific Northwest of the United States. Phytopathology 103:1130-1140. 
Pouzeshimiab, B., Razavi, M., Zare, R., and Momeni, H. 2016. The genetic structure and aggressiveness of Fusarium pseudograminearum populations in Iran. J. Plant Dis. Prot. 123:257-266.

Powell, J. J., Carere, J., Fitzgerald, T. L., Stiller, J., Covarelli, L., Xu, Q., Gubler, F., Colgrave, M. L., Gardiner, D. M., Manners, J. M., Henry, R. J., and Kazan, K. 2016. The Fusarium crown rot pathogen Fusarium pseudograminearum triggers a suite of transcriptional and metabolic changes in bread wheat (Triticum aestivum L.). Ann. Bot. 119:853-867.

Purss, G. S. 1966. Studies of varietal resistance to crown rot of wheat caused by Fusarium graminearum Schw. Queensl. J. Agric. Anim. Sci. 23:475-498.

Saad, A., Macdonald, B., Martin, A., Knight, N., and Percy, C. 2018. Winter cereal responses to root and crown rot pathogens in the field. Pages 24-25 in: Proc. 10th Australas. Soilborne Dis. Symp. V. Gupta and B. Hall, eds. Adelaide, Australia, Online at, https://www.appsnet.org/publications/proceedings/ASDS $\% 202018 \% 20$ Proceedings.pdf

Schilling, A. G., Möller, E. M., and Geiger, H. H. 1996. Polymerase chain reactionbased assays for species-specific detection of Fusarium culmorum, F. graminearum, and $F$. avenaceum. Phytopathology 86:515-522.

Schillinger, W. R., Papendick, R. I., Guy, S. O., Rasmussen, P. E., and van Kessel, C. 2006. Dryland cropping systems in the western United States. Pages 365-393 in: Dryland Agriculture, 2nd ed. G. A. Peterson, P. W. Unger, and W. A. Payne, eds. Agron. Monogr. 23. Amer. Soc. Agron., Madison, WI.

Smiley, R. W. 2009. Water and temperature parameters associated with winter wheat diseases caused by soilborne pathogens. Plant Dis. 93:73-80.

Smiley, R. W. 2019. Mechanized method to inoculate field soil to evaluate Fusarium crown rot of wheat. Plant Dis. https://doi.org/10.1094/PDIS-01-190215-RE

Smiley, R. W., Backhouse, D., Lucas, P., and Paulitz, T. 2009. Diseases which challenge global wheat production - root, crown, and culm rots. Pages 125-153 in: Wheat Science and Trade. B. F. Carver, ed. Wiley-Blackwell. Ames, IA.

Smiley, R. W., Collins, H. P., and Rasmussen, P. E. 1996. Diseases of wheat in long-term agronomic experiments at Pendleton, Oregon. Plant Dis. 80:813-820.

Smiley, R. W., Gourlie, J. A., Easley, S. A., and Patterson, L.-M. 2005a. Pathogenicity of fungi associated with the wheat crown rot complex in Oregon and Washington. Plant Dis. 89:949-957.
Smiley, R. W., Gourlie, J. A., Easley, S. A., Patterson, L.-M., and Whittaker, R. G. 2005 b. Crop damage estimates for crown rot of wheat and barley in the Pacific Northwest. Plant Dis. 89:595-604.

Smiley, R. W., Machado, S., Gourlie, J. A., Pritchett, L. C., Yan, G. P., and Jacobsen, E. E. 2013. Influence of semiarid cropping systems on root diseases and inoculum density of soilborne pathogens. Plant Dis. 97:547-555.

Smiley, R. W., Machado, S., Rhinhart, K. E. L., Reardon, C. L., and Wuest, S. B 2016. Rapid quantification of soilborne pathogen communities in wheat-based long-term field experiments. Plant Dis. 100:1692-1708.

Smiley, R. W., and Patterson, L.-M. 1996. Pathogenic fungi associated with Fusarium foot rot of winter wheat in the semiarid Pacific Northwest. Plant Dis. 80:944-949.

Smiley, R. W., and Yan, H. 2009. Variability of Fusarium crown rot tolerances among cultivars of spring and winter wheat. Plant Dis. 93:954-961.

Southwell, R. J., Moore, K. J., Manning, W., and Hayman, P. T. 2003. An outbreak of Fusarium head blight of durum wheat on the Liverpool Plains in northern New South Wales in 1999. Australas. Plant Pathol. 32:465-471.

Stephens, A. E., Gardiner, D. M., White, R. G., Munn, A. L., and Manners, J. M 2008. Phases of infection and gene expression of Fusarium graminearum during crown rot disease of wheat. Mol. Plant-Microbe Interact. 21:1571-1581.

Summerell, B. A., Burgess, L. W., and Klein, T. A. 1989. The impact of stubble management on the incidence of crown rot of wheat. Aust. J. Exp. Agric. 29:91-98

Summerell, B. A., Burgess, L. W., Klein, T. A., and Pattison, A. B. 1990. Stubble management and the site of penetration of wheat by Fusarium graminearum Group 1. Phytopathology 80:877-879.

Swan, L. J., Backhouse, D., and Burgess, L. W. 2000. Surface soil moisture and stubble management practice effects on the progress of infection of wheat by Fusarium pseudograminearum. Aust. J. Exp. Agric. 40:693-698.

Wildermuth, G. B., and McNamara, R. B. 1994. Testing wheat seedlings for resistance to crown rot caused by Fusarium graminearum Group 1. Plant Dis. 78:949-953.

Williams, K. J., Dennis, J. I., Smyl, C., and Wallwork, H. 2002. The application of species-specific assays based on the polymerase chain reaction to analyse Fusarium crown rot of durum wheat. Australas. Plant Pathol. 31:119-127.

Zadoks, J. C., Chang, T. T., and Konzak, C. F. 1974. A decimal code for the growth stages of cereals. Weed Res. 14:415-421. 